\title{
Evaluating Social Media Utilization on the Implementation of E- Government Goals in Tanzania
}

\author{
Herman Mandari ${ }^{1}$ and Daniel Koloseni ${ }^{2}$ \\ ${ }^{1}$ Computer Science Department, Institute of Finance Management \\ Dar es Salaam, Tanzania \\ ${ }^{2}$ Information Technology Department, Institute of Finance Management \\ Dar es Salaam, Tanzania
}

Correspondence should be addressed to: Herman Mandari; mandari@ifm.ac.tz

Received date:22 June 2016; Accepted date:12 July 2016; Published date:21 December 2016

Academic Editor: Isibor Osebor

Copyright @ 2016 . Herman Mandari and Daniel Koloseni . Distributed under Creative Commons CC-BY 4.0

\begin{abstract}
Social media provide a platform that can be used by the government to communicate with its citizens. Most governments worldwide are taking advantages of the increased number of citizens who are using social media to provide required public services and information. The utilization of social media by the government increases the level of transparency and citizen's participation in various public activities which may result into institutional changes. Despite the numerous advantages offered by social media, the Government of Tanzania has not yet adequately explored the opportunity offered by the social media. A desktop survey was conducted to evaluate the utilization of social media in 84 Tanzania government institutions. The results revealed that only $28.5 \%$ of the public websites were connected to social media. Furthermore, most of the social media platforms used by various government institutions are inactive and less frequently used. Therefore, the current study recommends speeding up the adoption and utilization of social media platform to provide information related services to citizens in Tanzania public sector.
\end{abstract}

Keywords: E-government, Social media, Adoption

\section{Introduction}

The World Wide Web has made superficial changes on people's lives in different aspects, such as the way people conduct business, communicate and socialize (Agarwal \& Mital,2009). This means that, the web has become a central part of people's lives. The transition from Web 1.0 to Web 2.0 has introduced new web features which make

Cite this Article as: Herman Mandari and Daniel Koloseni (2016), "Evaluating Social Media Utilization on the Implementation of E- Government Goals in Tanzania ", Journal of African Research in Business \& Technology, Vol. 2016 (2016), Article ID 759473, DOI: 10.5171/2016.759473 
the web more useful to citizens by allowing them to create and distribute information (O'Reilly, 2007). Currently, the web users are not just consumers but also creators and publishers of web contents. The ability of Web 2.0 has provided more chance to people to be involved in different online communications through easy exchange of information and in the fast way. Web 2.0 provides different tools which enable users to easily create collaborative website, create personal accounts in existing social media tools and populate them with contents which can be consumed by others. The effect of Web 2.0 can be realized through the availability of social media which have emerged as one of the great platforms of communication in our society. Nowadays, citizens are using social media to communicate about social, political, and economic issues in easy and rapid way (Saulles, 2011). Furthermore, social media are easily accessible to people with Internet enabled mobile devices (Khasawneh \& AbuShanab, 2013). Governments world-wide have shifted from traditional, brick-andmortar to electronic government (egovernment) in order to serve citizens better. The main purpose of using e-government is to increase transparency, citizens' participation, accountability and to provide correct and timely information to citizens (Raman, 2008). Moreover, the use of electronic means in disseminating public information tends to cover a large number of citizens at a less cost (Manoharan, 2014).

Development in social media has triggered various governments worldwide to adopt social media as one of the possible alternatives to accomplish various egovernment goals (Bertot et al. 2010; Khasawneh \& Abu-Shanab, 2013). Tanzania has also adopted e-government in providing public services to its citizens. Tanzania egovernment goals include: delivery of high quality services with improved accessibility, responsiveness, and efficiency; to strengthen coordination of activities across government stakeholders and knowledge sharing; and to provide integrated, secured and innovative solutions to improve quality of services and work processes (URT, 2012). Thus, effective adoption of social media may assist the government in achieving e-government goals at a lower cost. Despite the importance of social media in public sector, little is known about the status of social media utilization by the government of Tanzania. Thus, this study contributes to the body of knowledge by shedding light on our understanding of the status of utilization of social media by the Government of Tanzania to provide information services to citizens. Additionally, this study provides recommendations for policy makers, decision makers and egovernment practitioners on the effective utilization of social media in public sector in order to take full advantage of social media.

\section{Literature Review}

\section{Social Media}

Social media refer to the application of technology to enable people to easily communicate online and at an affordable cost (Bonsón et al., 2012). Various studies have shown that social media are growing very fast (Khasawneh \& Abu-Shanab, 2013), the reasons being the power of human network in interactions, they allow two-way communication between the users rather than just broadcasting the message. Also social media use all forms of multimedia information to enable communication in society (Landsbergen, 2010). Furthermore, social media allow users to use Web 2.0 tools to create online identity and list of friends and followers who in turn may engage in various online social conversations. The most used Web 2.0 tools include: (1) Weblog which is the type of website owned and maintained by an individual or an organization who constantly update it by posting various information. Also Weblog allows other people to read and comment on the available contents (Harris \& Rea, 2009); (2) Content communities which have the purpose of sharing different information in different formats; (3) Social networking site which is an online community allowing 
people with different interests to share private and public messages. Social networking sites are very popular because of the way they enable a two way communication and interaction among users. (4) Collaborative projects which allow the creation of collaborative web contents. The most popular social networking sites include Facebook which was launched in 2004, twitter launched in 2006. While Facebook provided unlimited number of characters to post, Twitter allows users to create and send short messages only 140 characters called tweet. Additionally, Twitter allows different people subscribed to the user profile, also known as followers, to read and re-tweet (Harris \& Rea 2009). YouTube launched in 2003 allows people to upload audios and videos which can be viewed by different users. Blogger allows users to post multiple entries and is limited to 500 characters. All of these social media have a different model of enabling communication among their users.

Social media have recently gained more popularity due to the development of mobile and wireless technologies (Sanders, 2010). The availability of Internet enabled mobile devices such as smartphones and tablets enables users to share online resources anywhere anytime. Mobile devices allow easy creation of contents such as videos, audios, and text and distribute them across a number of social media. Therefore, the presence of mobile devices has accelerated the uses of social media in the society.

\section{E-Government}

Most governments are struggling in providing public services with information, the reasons being scattered and increasing population (Al-Mamari et al., 2015). Furthermore, the traditional methods used in providing public services tend to cause delay of services and provide room for bureaucracy in accessing public information and services (Coleman, 2006). To address these challenges, different governments worldwide adopted e-government as a method to provide public services and information. E- government is defined as the application of Information and Communication Technology (ICT) to provide government services to stakeholders (Huang \& Bwoma, 2003; Muir \& Oppenheim, 2002). Therefore, through the application of ICT, particularly the Internet and web technology, the government may increase transparency by informing citizens about the various issues being addressed by the government, enable easy accessibility of public services and information at affordable cost (Stiftung, 2002; Eggers, 2004); and reduce the bureaucracy and corruption which may arise as a result of using traditional methods (D'agostino et al., 2011). Furthermore, e-government may be used to provide awareness on various national activities which may increase the eparticipation of citizens. The full utilization of e-government may help to reduce the communication gap and digital divide which exist between the government and the citizens. The use of e-government is mostly successfully adopted in developed countries as compared to developing countries (UN, 2014). The reason being lack of capital required to invest in developing egovernment infrastructure. Therefore, to increase e-government utilization there is necessity to explore other available cost effective alternatives which can be used to achieve the e-government goals particularly in least developing countries.

\section{Social Media in Government}

One of the key success factors of egovernment utilization is the extent to which social media are utilized in the public sector (UN, 2014). The application of social media in public sector produces a number of advantages. Among the advantages is eparticipation which enables citizens to participate in various national activities (UN, 2014). E-participation empowers citizens both receiver and active partner of the government in creating and sharing information. For the government to increase e-participation, it is imperative to adopt existing social media platforms which are familiar to citizens rather than creating new 
ones (Chang \& Kannan, 2008). Through social media, the government can collect citizens' comments via feedbacks and views on different issues. Comments collected may help the government to understand the perception of the citizens and devise appropriate measures on the issue. Furthermore, social media may be used to instantly disseminate information to the society to inform citizens of any current emergency or any expected event (Magro, 2012). For example, in emergency situations such as floods and earthquakes, social media could assist the government to inform the citizens on evacuation plans and safety tips.

The application of social media is considered as a cost effective method in government service delivery. This is because they do not require heavy investment for the set-up since they do not run in government platforms. Social media run on a private platform which allows individuals or organizations to create and own accounts. This helps to reduce the cost which may be incurred by the government in developing and maintaining its own social media platform for communicating with citizens (Dadashzadeh, 2010). Therefore, the utilization of social media in the public sector does not only improve services' accessibility but also increases transparency and hence good governance.

The utilization of social media is not without challenges. Various challenges which may be encountered by the government during the utilization of social media include: (1) social media accessibility requires large Internet bandwidth usage, (2) Misuse of social media, such as posting personal issues or unrelated information to government services. (3) In addition, reputation damage may occur due to the use of abusive language, text, audio and video (Pettersson \& Karlström, 2011; Kavanaugh et al., 2012).

\section{Tanzania e-Government Initiative}

Tanzania government adopted the egovernment strategy in 2009. Among the goals stipulated in the strategy was the establishment of the Electronic Government Agency (eGa) which was officially launched in 2012. The agency is responsible for ensuring that, all the government institutions are using ICT to deliver public services and information to accelerate the work processes, increases the transparency and accountability while reducing the cost of operations. eGa is striving to reduce the digital divide between the government and citizens which is considered to be a major barrier for accessibility of public services and information. To date, the government has managed to establish various ICT infrastructures such as websites for various government institutions. However, a recent study from United Nations shows that Tanzania government is not doing well in the use of ICT to provide public services (UN, 2014). The country is listed number 146 out of 193 countries which is a seven position drop from 2012 UN e-government survey. Furthermore, the e-Government Development Index (EGDI) for Tanzania is 0.2764 which is below the world average index. The world average EGDI is 0.4712 (UN, 2014). The EGDI score indicates that Tanzania government has limited resources to successfully implement e-government initiatives. To achieve e-government goals may be difficult due to lack of enough resources to put required infrastructures in place. To address the issue of resource limitations for e-government initiatives, it is proposed to use social media because they do not require huge investment (UN, 2014).

\section{Methodology}

This study evaluated the usage of various social media in Tanzania public sector to communicate with citizens. According to eGa, Ministries, Department, Agencies and Authorities (MDA), websites are the official online tools for disseminating government information (URT, 2012). This study considered all the MDA websites in the evaluation on the utilization of social media tools. It is expected that social media tools should be attached over the organization

Herman Mandari and Daniel Koloseni (2016), Journal of African Research in Business \& Technology, DOI: 10.5171/2016. 759473 
website to notify citizens on their presence in social media. Desktop survey was conducted by visiting each organization website homepage which is accessible through the national portal website (www.tanzania.go.tz). The observation was conducted to check if the organization has any account on Facebook, Twitter, and YouTube, which are considered to be the most popular social media globally (UN, 2014). Also, weblog was included because it is considered as one of the popular social media for communication in Tanzania. The authors were interested to know if the organization owns the blog and if the contents are up to date. Furthermore, the researchers were interested to know which social media among the four is mostly used in public sector, and if there is any existing social media policy used by government to disseminate public services and information.

\section{Findings and Discussion}

Evaluation of all MDA and Authorities were conducted in July 2015, the survey was conducted by evaluating 110 government institutions' websites which comprised of 40 authorities, 25 agencies, 26 ministries and 19 independent departments. The researchers visited each particular government institution home page through the website domain name. Among the visited websites, 15 authorities' websites, 4 agencies websites, 5 ministries websites and 2 independent department's websites were inaccessible and therefore were excluded from further analyses. The results of analysis are reported in table 1 , table 2 and figure 1.

Table 1: Government institution using social media

\begin{tabular}{|l|c|c|c|}
\hline & Account Available & No Account & Total website \\
\hline Authorities & $9(36.0 \%)$ & $16(64.0 \%)$ & 25 \\
\hline Agencies & $5(23.8 \%)$ & $16(76.2 \%)$ & 21 \\
\hline Ministries & $7(33.3 \%)$ & $14(66.7 \%)$ & 21 \\
\hline $\begin{array}{l}\text { Independent } \\
\text { Department }\end{array}$ & $3(17.6 \%)$ & $14(82.4 \%)$ & 17 \\
\hline Total & $24(28.5 \%)$ & $60(71.5 \%)$ & 84 \\
\hline
\end{tabular}

The findings in table 1 indicate that only $28.5 \%$ of the analyzed government institutions uses social media. This implies that most of the government institutions do not have any social media account and therefore, only little public information can be accessible via social media from government institutions websites. Some of the government institutions have included social media icons in their websites, but the links to social media are inactive. This indicates that these government institutions do not own any of the displayed social media accounts although the intention to own social media in the near future is there. Furthermore, some active social media accounts were used to communicate nongovernment information. Further, some government institutions own social media accounts, however they are not actively posting events on those social media accounts and contents of the posts are not timely and frequently updated. This tendency in long run may discourage citizens, followers of respective social media accounts to depend on the social media accounts of the government institutions as one of the instant sources of information from the government. This finding shows that, the utilization of social media Tanzania government institutions is still very low. 


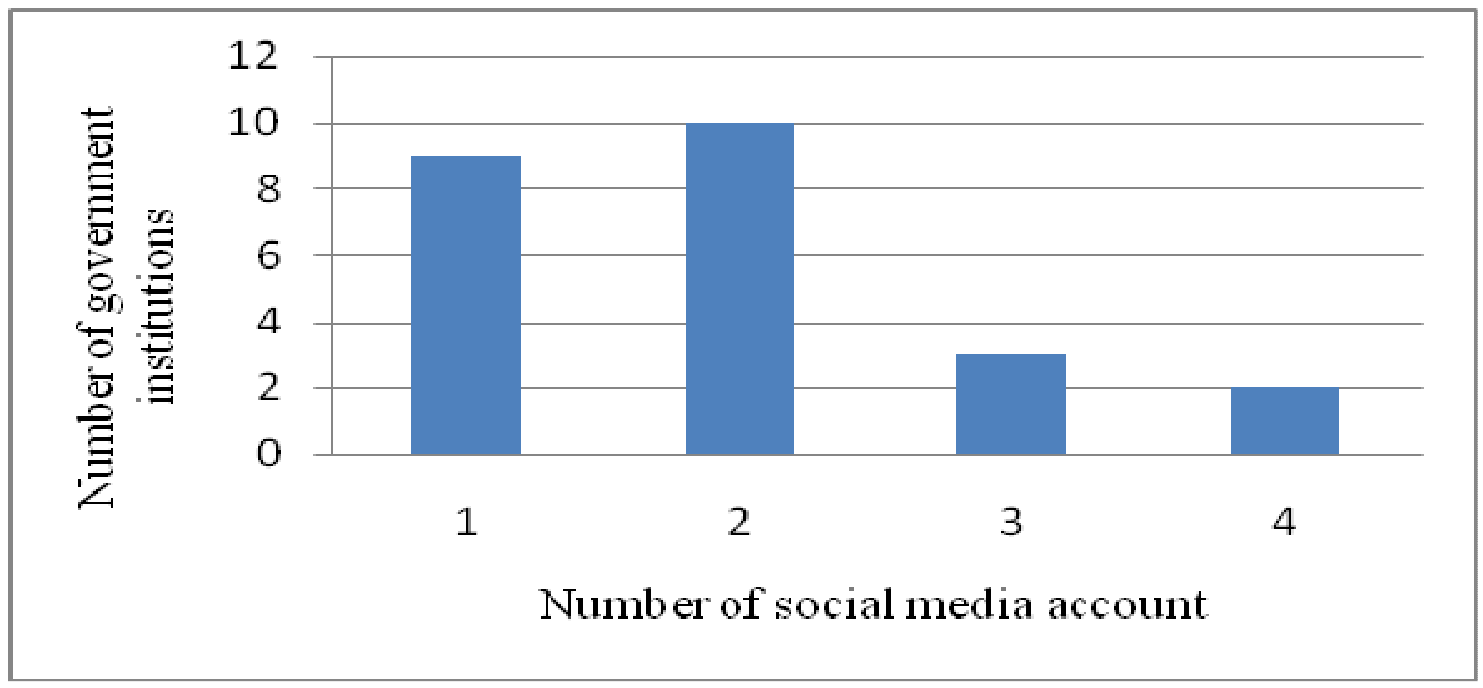

Figure 1: Ownership of social media account

We have noticed that most of the government institutions do not own all major four social media accounts (refer figure 1). The majority owns two accounts while only two government institutions own all four social media accounts. Government institutions which own all four major social accounts are Dar es Salaam Stock Exchange (DSE) and Tanzania meteorological Agency (TMA). This may limit the accessibility of social media information by citizens; since some of the citizens may use different social media accounts from the ones currently used by the government institutions. Consequently, some of the citizens may miss important information from the government.
The results in table 2 show that, Facebook is the most used social medium by the government institutions to communicate with citizens. Facebook is preferred, since it is the most popular social medium used by many people in Africa (Review African Business, 2015). Thus, most of the government institutions prefer Facebook to publish their content in order to reach more citizens. Also, the survey reveals that there is no government social media policy and regulation used to regulate the utilization of social media in the public sector.

Table 2: Number of Social Media Accounts in Government Agencies

\begin{tabular}{|l|l|l|l|l|}
\hline & Facebook & Twitter & YouTube & Blog \\
\hline Authorities & 9 & 7 & 1 & 0 \\
\hline Agencies & 4 & 4 & 3 & 1 \\
\hline Ministries & 5 & 1 & 1 & 3 \\
\hline $\begin{array}{l}\text { Independent } \\
\text { Department }\end{array}$ & 2 & 2 & 1 & 1 \\
\hline Total (N)* & 20 & 14 & 6 & 5 \\
\hline Total (\%) & $(44.4 \%)$ & $(31.1 \%)$ & $(13.3 \%)$ & $(11.1 \%)$ \\
\hline
\end{tabular}

${ }^{*} \mathrm{~N}=$ Total number of social media accounts 


\section{Conclusion and Recommendations}

Social media are cost effective platforms suitable for the least developing countries (LDCs) such as Tanzania and which have widely been used as a medium of communication between the government institutions and the citizens. However, this study found that their utilization in the Tanzania government institutions is still low. The achievement of e-government initiatives depends among other things on the interactions between the government institutions and the citizens through social media. Underutilization of social media by the government institutions may subsequently lead to failure to achieve egovernment initiatives' goals.

Most of the government institutions are informally using social media to disseminate government information without any guidelines or policy. However, such approach used by government institutions is not advised (Hrdinová et al., 2010). Therefore, this study recommends the government of Tanzania to formulate the social media policy and guidelines that will be used by government institutions. These guidelines will help to guide proper utilization of social media and as a mechanism of enforcing government institutions to use social media for communication with citizens on various government issues. Additionally, these guidelines along with cyber security law may help to address the challenges of using social media to deliver e-government services as reported in the literature review section. Further, to ensure timely and up to date information communicated through social media, the government social media accounts should be regularly updated with relevant information.

\section{Limitations and Future Research}

This study concentrated only on Ministries, Authorities, Agencies and Independent Departments (MDA's). However, other government institutions such as higher learning institutions, hospitals, regional and districts' offices which have websites and may be using social media can be assessed as well. Therefore, further research may include all categories of government institutions in order to have a broader picture on the state of social media utilization to attain egovernment goals in Tanzania. Additionally, future empirical research may be conducted to explore factors influencing the adoption of social media by the government of Tanzania.

\section{References}

1. Agarwal, S. \& Mital, M., 2009. An exploratory study of Indian university students' use of social networking web sites: Implications for the workplace. Business Communication Quarterly, 72(1), pp.105110.

2. Al-Mamari, Q., Corbitt, B. \& Gekara, V., 2015. E-Government adoption and implementation in Oman: A government perspective.

3. Bertot, J.C. et al., 2010. Social media technology and government transparency. Computers \& Education, 43(11), pp.53-59.

4. Bonsón, E. et al., 2012. Local egovernment 2.0: Social media and corporate transparency in municipalities. Government information quarterly, 29(2), pp.123-132.

5. Chang, A.M. \& Kannan, P.K., 2008. Leveraging Web 2.0 in government.

6. Coleman, S., 2006. African egovernance-opportunities and challenges. Ox-ford University Press, University of Oxford.

7. D'agostino, M.J. et al., 2011. A study of egovernment and e-governance: An empirical examination of municipal websites. Public Administration Quarterly, pp.3-25.

8. Dadashzadeh, M., 2010. Social media in government: From eGovernment to eGovernance. Journal of Business \& Economics Research, 8(11). 
9. Eggers, W.D., 2004. Boosting egovernment adoption. In Deloitte researchpublic sector, Canada, FTA Annual Conference.

10. Harris, A.L. \& Rea, A., 2009. Web 2.0 and virtual world technologies: A growing impact on IS education. Journal of Information Systems Education, 20(2).

11. Hrdinová, J., Helbig, N. \& Peters, C.S., 2010. Designing social media policy for government: Eight essential elements., Center for Technology in Government, University at Albany.

12. Huang, Z. \& Bwoma, P.O., 2003. An Overview of Critical Issues of e-government. Issues of Information Systems, 4(1), pp.164170.

13. Kavanaugh, A. et al., 2012. Social media use by government from the routine to the critical. Government Information Quarterly, 29(4), pp.480-491.

14. Khasawneh, R. \& Abu-Shanab, E., 2013. E-Government and Social Media Sites: The Role and Impact. World Journal of Computer Application and Technology, 1(1), pp.10-17.

15. Landsbergen, D., 2010. Government as part of the revolution: Using social media to achieve public goals. In In Proceedings of the 10th European conference on e-government. pp. 243-250.

16. Magro, M.J., 2012. A review of social media use in e-government. Administrative Sciences, 2(2), pp.148-161.

17. Manoharan, A., 2014. E-government and Websites: A Public Solutions Handbook, Routledge.

18. Muir, A. \& Oppenheim, C., 2002. National Information Policy developments worldwide in electronic government. Journal of Information Science., 28(1), pp.173-186.

19. O'Reilly, T., 2007. What Is Web 2.0: Design Patterns and Business Models for the
Next Generation of Software. International Journal of Digital Economics, 65(1), pp.17-37.

20. Pettersson, D. \& Karlström, P., 2011. Reputation as a Product: Politicians in Social Media. In Proceedings of The second International Conference on Reputation, ICORE.

21. Raman, V. V, 2008. Examining the'e'in government and governance: A case study in alternatives from Bangalore City, India. The Journal of Community Informatics, 4(2).

22. Review African Business, 2015. Top 10 African Social Networks. African Business Review.

23. Sanders, T., 2010. Government 2.0: Building communities with Web 2.0 and social networking.

24. Saulles, M., 2011. Social media and local government in England: who is doing what? In Proceeding of the 11th European Conference on e-Government, Ljubljana, Slovenia.

25. Stiftung, B., 2002. Balanced EGovernment: E-Government - Connecting Efficient Administration and Responsive Democracy. A study by the Bertelsmann Foundation.

26. UN, 2014. United Nations E-Government Survey, New York, USA.

27. URT, 2012. Tanzania E-Government Strategy, Dar es Salaam.

Herman Mandari and Daniel Koloseni (2016), Journal of African Research in Business \& Technology, DOI: 10.5171/2016. 759473 